\title{
QUANTUM-CHEMICAL SIMULATION OF THE CLUSTER STRUCTURE OF LIQUID $N$-HEPTANOL
}

\author{
P. GOLUB, V. POGORELOV, I. DOROSHENKO
}

PACS 36.40.Mr

Different molecular aggregations formed in liquid heptanol due to the hydrogen bonding are investigated. Using the methods of quantum-chemical simulation, the preference of the aggregations involving more than 5 molecules is shown. The correctness of the conclusions is established by the comparison of the obtained results with experimental data.

\section{Introduction}

Nowadays, simple alcohols are among the most important substances for the detailed research of hydrogen bonded systems due to their ability to form complex structures in the liquid phase. These structures may be closed or opened cycles involving three or more molecules hold together by hydrogen bonds. The analysis of the cluster formation processes in such substances can deepen our understanding of the dynamics of hydrogen bonded model systems.

There are a great number of publications devoted to the investigations of the simplest alcohols such as methanol and ethanol. Small methanol clusters were studied by means of vibrational spectroscopy in the pure form and the gas phase [1-5]. A special attention was paid to the investigations of the methanol cluster formation in inert gas matrices [6-10] and in supersonic jets $[11,12]$. Now one of the most powerful methods is the investigation of alcohol clusters in helium nanodroplets. This ingenious researching technique allows one to take measurements for isolated clusters of a definite size [13].

But, in the case of higher alcohols with long alkyl chains, there are only few articles. Nucleation rates of $n$-alcohols (up to the $n$-octanol included) in a laminar flow were established in [14], and the ice nucleation by long-chain alcohols was studied in [15] and some other articles. It is clear that the information accumulated till today about higher alcohols is not enough if someone wants to do far-reaching conclusions.

In this work, we will try to full up the gap in knowledge about higher alcohols. Using quantitative methods of quantum chemistry, we have simulated the en- ergy parameters and IR spectra of $n$-heptanol clusters $\left(\mathrm{C}_{7} \mathrm{H}_{15} \mathrm{OH}\right)_{n}$ with $n$ from 2 up to 8 molecules. Having compared the obtained results with the experimental spectrum of liquid heptanol, we determine which sort of clusters mainly exists in liquid heptanol.

\section{Quantum-Chemistry Simulation Details}

For the quantum-chemistry calculations, the program package Gaussian 03 and the Hartree-Fock method with 6-31G(d,p) basis set were chosen.

As the first stage of the preparation for calculations, the structures close to the expected cyclic or chain-like clusters were manually build in the Gaussian 03 Viewer program. After these manipulations, the equilibrium geometries for all the specified structures were calculated. Then the obtained optimized structures were used for the calculations of the corresponding binding energies of the investigated clusters. After that, the obtained results were compared with those of analogous calculations made for the same numbers of molecules but not involved in the interaction. Having divided the energy difference by the number of hydrogen bonds in the structure, we have obtained the energy per one hydrogen bond. The IR absorption spectra of all such clusters were calculated as well. The energy values and the calculated IR spectra have clearly indicated that the hydrogen bonding really exists in these structures, and such clusters are really formed.

\section{Results}

The calculated spectrum of a non-bonded $n$-heptanol molecule is presented in Fig. 1. It is clearly seen that, in the region of $\mathrm{O}-\mathrm{H}$ stretch vibrations $(3000-4000$ $\mathrm{cm}^{-1}$ ), there is only one vibration with a frequency of $3600 \mathrm{~cm}^{-1}$.

The results of calculations of the optimized geometry and IR spectra for $n$-heptanol clusters consisting of two, three, four, and five molecules bonded consequently by intermolecular hydrogen bonds are presented in Fig. 2. 


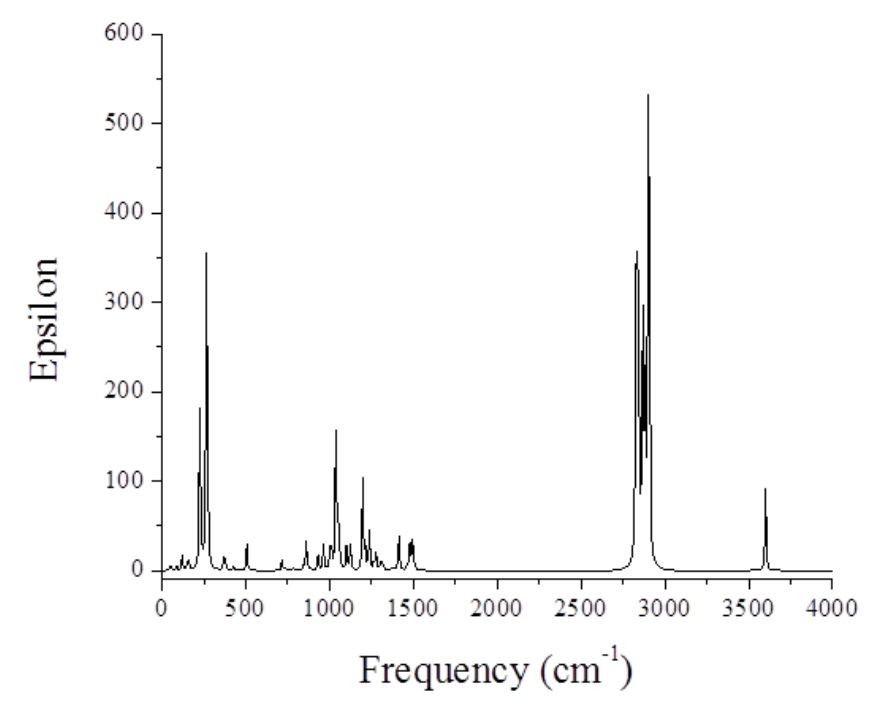

Fig. 1. Calculated IR spectrum of an $n$-heptanol molecule

The most interesting part of the spectra is the region of hydroxyl group stretch vibrations (3000-4000 $\mathrm{cm}^{-1}$ ), because the position of this band is an indicator of the existence and the strength of the hydrogen bonding between alcohol molecules. As is seen from Fig. 2, the number of vibrational bands in the region of $\mathrm{O}-\mathrm{H}$ stretch vibrations corresponds to the number of molecules forming the cluster. The position of one band with a frequency of $3603 \mathrm{~cm}^{-1}$ does not depend on the number of molecules in the cluster. It corresponds to vibrations of a free $\mathrm{OH}$ group not involved in the hydrogen bond formation. The other bands are shifted to the low-frequency range and are assigned to vibrations of H-bonded hydroxyl groups. Moreover, the value of their shift increases with the number of molecules: in the case of a dimer, this band has a frequency of $3474 \mathrm{~cm}^{-1}$; for a three-molecular cluster, they are 3376 and $3413 \mathrm{~cm}^{-1}$, for a tetramer - 3305, 3392 , and $3402 \mathrm{~cm}^{-1}$, and for a pentamer - 3239, 3288, 3330 , and $3337 \mathrm{~cm}^{-1}$.

The results of the quantum-chemical simulation of optimized structures and the calculated IR spectra for cyclic clusters of heptanol consisting of three, four, and five molecules are presented in Fig. 3. It is remarkable that, in the case of a pentamer (in contrast to the smaller clusters), the oxygen atoms do not lie in one plane. Obviously, as the size increases, the cyclic clusters become too bulky, and long alkyl chains try to "compensate" the repulsion between them.

Since there are no free hydroxyl groups in the cyclic heptanol clusters, where the hydrogen bonds form closed rings, their IR spectra differ from the previous ones by the absence of vibrations of non-bonded hydroxyls. But
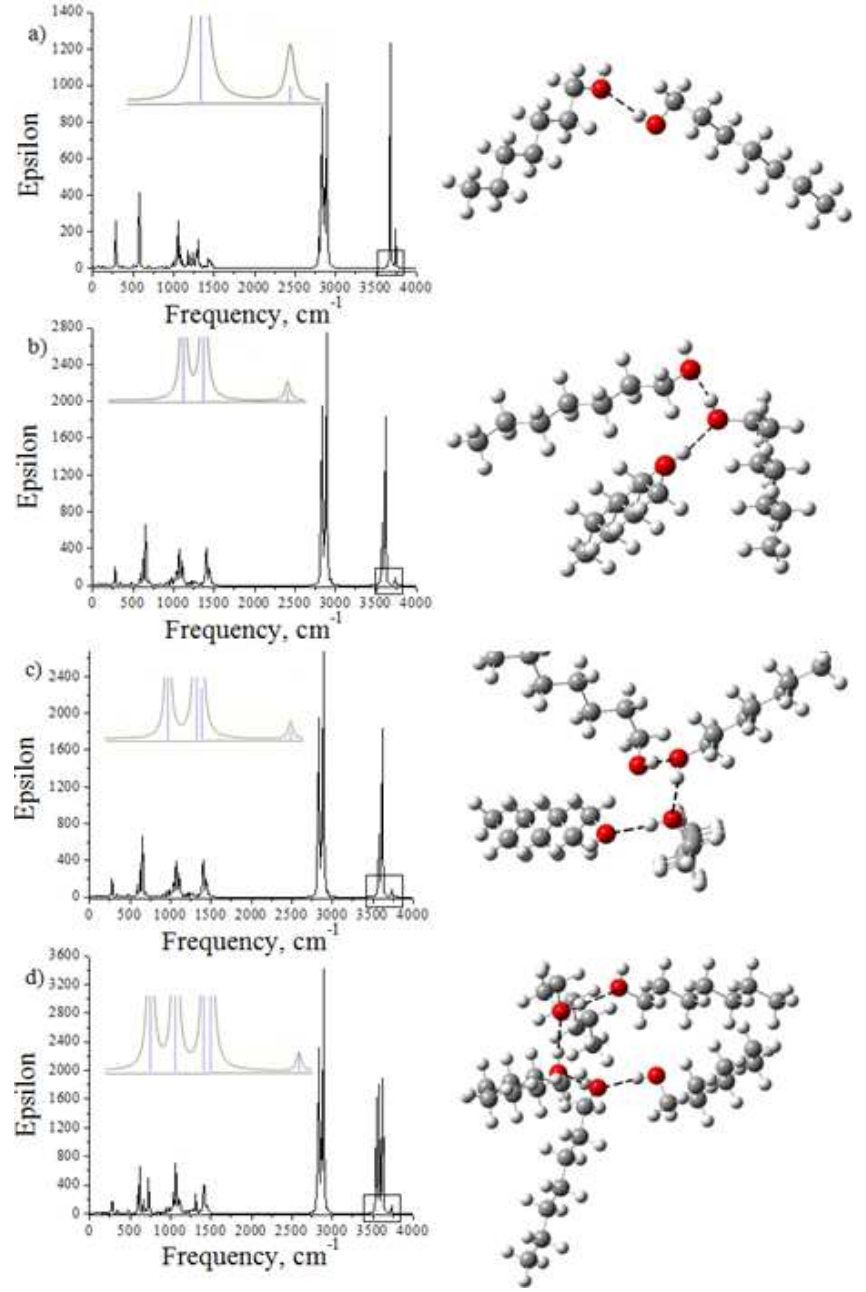

Fig. 2. IR spectra and the optimized geometry for $n$-heptanol in different chain-like clusters: $a$ ) two molecules, $b$ ) three molecules, c) four molecules, $d$ ) five molecules

the other peculiarities are the same: the number of vibrational bands in the region of $\mathrm{O}-\mathrm{H}$ stretch vibrations corresponds to the number of molecules in a cluster, and their red shift increases with the number of molecules. So, for a cyclic trimer, we have three bands with frequencies of 3386,3424 , and $3429 \mathrm{~cm}^{-1}$; for a cyclic tetramer - 3218, 3278, 3289, and $3320 \mathrm{~cm}^{-1}$, for a pentamer $3185,3244,3250,3278$, and $3294 \mathrm{~cm}^{-1}$.

Under the aggregation of heptanol molecules, in accordance to the results of the quantum-chemical simulation, the bond lengths in them, especially the distances between atoms $\mathrm{O}$ and $\mathrm{H}$ directly involved in the formation of intermolecular H-bonds, change. The calculated lengths of intermolecular and intramolecular $\mathrm{OH}$ bonds are presented in Table 1 . There is the remarkable 
$\mathrm{T}$ a b l e 1. Calculated lengths of intermolecular and intramolecular $\mathrm{OH}$ bonds

\begin{tabular}{c|c|c|c|c}
\hline Number of molecules & \multicolumn{2}{|c|}{ Cycle } & \multicolumn{2}{c}{ Open structure } \\
\hline & $\begin{array}{c}\text { Intramolecular OH } \\
\text { bond, } \AA\end{array}$ & $\begin{array}{c}\text { Intermolecular OH } \\
\text { bond, } \AA\end{array}$ & $\begin{array}{c}\text { Intramolecular OH } \\
\text { bond, } \AA\end{array}$ & $\begin{array}{c}\text { Intermolecular OH } \\
\text { bond, } \AA\end{array}$ \\
\hline 2 & - & - & 0.945 & 2.034 \\
3 & 0.950 & 2.015 & 0.950 & 1.957 \\
4 & 0.953 & 1.905 & 0.951 & 1.938 \\
5 & 0.954 & 1.882 & 0.952 & 1.912 \\
6 & 0.954 & 1.880 & 0.951 & 1.913 \\
7 & 0.953 & 1.887 & 0.952 & 1.910 \\
8 & 0.953 & 1.891 & 0.952 & 1.903 \\
\hline
\end{tabular}
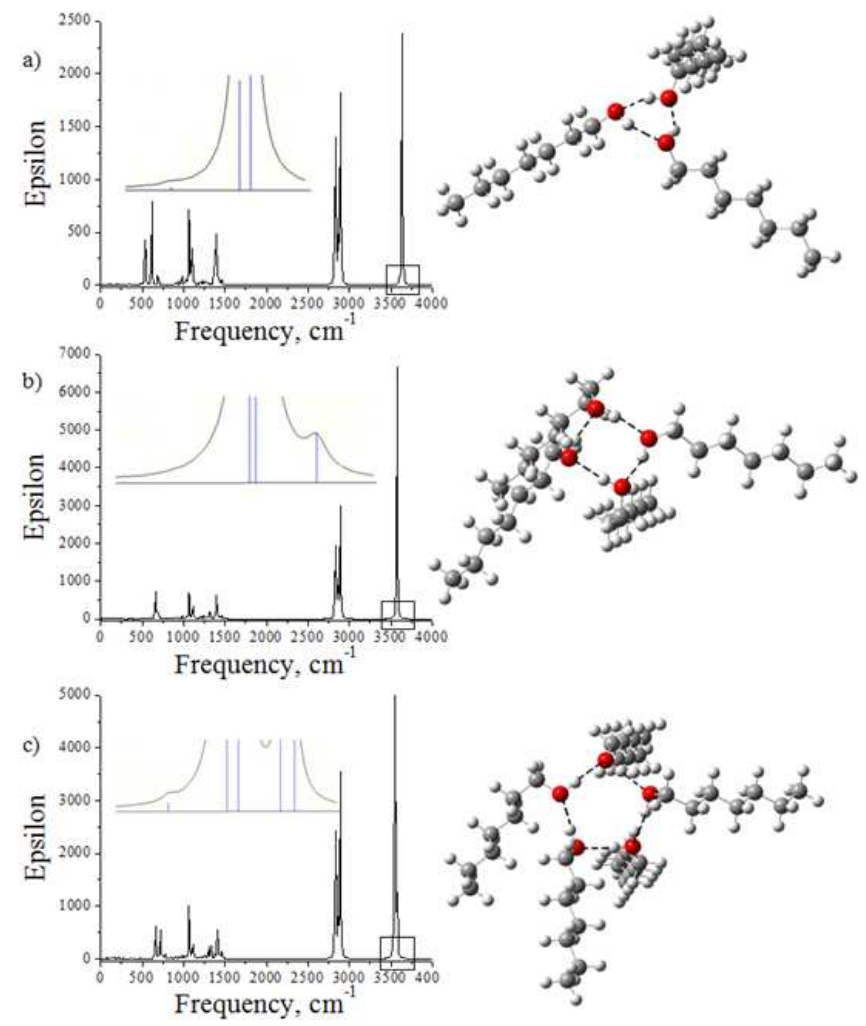

Fig. 3. Calculated IR spectra and the optimized geometries of cyclic heptanol clusters consisting of three $(a)$, four $(b)$, and five (c) molecules

regularity for the considered clusters: as the number of molecules involved in the cyclic structure increases, the average length of intramolecular $\mathrm{OH}$ bonds increases, while the average length of intermolecular $\mathrm{OH}$ bonds decreases. This means that the heptanol clusters become more "tight," as their volume increases, and, as a sequence, they become more stable. However, reaching the value of 5 or 6 molecules in the cluster, the distances between $\mathrm{O}$ and $\mathrm{H}$ atoms remain practically the same both for the cyclic clusters and for the open structures.

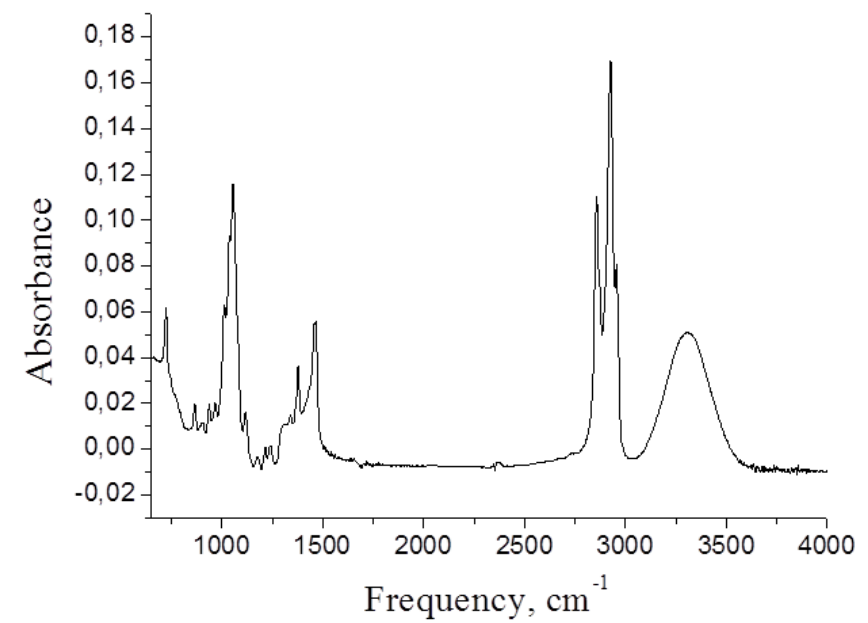

Fig. 4. Experimentally registered IR spectrum of heptanol in the liquid phase

The calculated energies of different heptanol clusters are presented in Table 2. It is seen that the value of bonding energy per one hydrogen bond in clusters linearly depends on the number of molecules forming a cluster, i.e. the larger clusters are more profitable. Moreover, there is practically no difference between the energies of cyclic and open clusters. This means that, in real liquid alcohol, the both structures can exist with equal probabilities.

In order to determine which types of clusters exist in liquid heptanol, the comparison of the experimental data and the results of quantum-chemical simulations was made. The experimentally registered IR spectrum of heptanol in the liquid phase is presented in Fig. 4. It was registered at the Laboratory of Fourier-Transform IR Spectroscopy at the Vilnius University using a Bruker FTIR spectrometer Vertex 70 with an MCT detector. The spectrum was registered in the spectral range 650 $4000 \mathrm{~cm}^{-1}$ with a resolution of $4 \mathrm{~cm}^{-1}$.

Paying attention again to the region of $\mathrm{O}-\mathrm{H}$ stretch vibrations $\left(3000-4000 \mathrm{~cm}^{-1}\right)$, one can notice a very 
QUANTUM-CHEMICAL SIMULATION

T a b l e 2. Calculated energies for heptanol clusters

\begin{tabular}{c|c|c|c|c}
\hline Number of molecules & \multicolumn{2}{|c|}{ Cycle } & \multicolumn{2}{c}{ Open structure } \\
\hline & $\begin{array}{c}\text { Total system energy } \\
\text { hartree }\end{array}$ & $\begin{array}{c}\text { Energy per one hydrogen } \\
\text { bond, kcal/mol }\end{array}$ & $\begin{array}{c}\text { Total system energy } \\
\text { hartree }\end{array}$ & $\begin{array}{c}\text { Energy per one hydrogen } \\
\text { bond, kcal/mol }\end{array}$ \\
\hline 2 & - & - & -698.566 & -2.09 \\
3 & -1047.863 & -6.07 & -1047.859 & -7.84 \\
4 & -1397.159 & -7.37 & -1397.150 & -7.95 \\
5 & -1746.452 & -7.78 & -1746.441 & -8.00 \\
6 & -2095.744 & -7.95 & -2095.728 & -7.53 \\
7 & -2445.034 & -7.89 & -2445.022 & -7.95 \\
8 & -2794.322 & -7.67 & -2794.312 & -7.89 \\
\hline
\end{tabular}

broad band with the maximum near $3300 \mathrm{~cm}^{-1}$, which belongs to vibrations of the H-bonded hydroxyls, and a very weak feature near $3670 \mathrm{~cm}^{-1}$ corresponding to vibrations of free hydroxyl groups. Comparing the distance between these two bands with the calculated splitting between the bands of free and bonded OH-group vibrations in the IR spectra of different heptanol clusters, one can make conclusion about the size of molecular clusters in liquid alcohol.

The calculated splitting between the band of free hydroxyl group vibrations $\left(3603 \mathrm{~cm}^{-1}\right)$ and the one of the bonded ones $\left(3474 \mathrm{~cm}^{-1}\right)$ in a heptanol dimer is $189 \mathrm{~cm}^{-1}$. The average calculated splitting for a trimer is $208 \mathrm{~cm}^{-1}$, for a tetramer $-236 \mathrm{~cm}^{-1}$, for a pentamer $304 \mathrm{~cm}^{-1}$, and for a hexamer $-364 \mathrm{~cm}^{-1}$. Since this distance in the experimental spectrum is about $370 \mathrm{~cm}^{-1}$, we can conclude that, in the liquid phase, the clusters consisting of more than 5 molecules prevail.

So, a large difference in the intensities of the bands at $3300 \mathrm{~cm}^{-1}$ and $3670 \mathrm{~cm}^{-1}$ can be explained by the fact that, in large clusters, there is only one free hydroxyl group per 6,8 , or even more ones involved in the $\mathrm{H}$ bond formation. In the calculated spectra for such clusters, the absorption at $3603 \mathrm{~cm}^{-1}$ is $20-30$ times weaker than that in the region $3200-3400 \mathrm{~cm}^{-1}$. Moreover, in the cyclic clusters, there are no free hydroxyls at all. If we assume that open and closed structures exist in the liquid phase in equal numbers (remembering the equal values of the bonding energies for the cycles and the open clusters), then this difference becomes even twice larger.

\section{Conclusion}

The quantum-chemical calculations of the structural and spectral characteristics of the cluster structure of $n$ heptanol are carried out, by using the possibilities of the program set Gaussian 03. The optimal geometries, bonding energies, and IR spectra for various hep- tanol clusters are calculated. With regard for the results of quantum-chemical simulations (the frequencies of the vibrational bands corresponding to bonded hydroxyl groups in clusters of various sizes, the higher energy profitability of larger clusters, and the equal bonding energies for cycles and open structures), we conclude that, in the liquid phase of $n$-heptanol, there are the cyclic and open clusters consisting of more than 5 molecules in equal proportions. This conclusion can be confirmed by the difference in the intensities of the absorption bands corresponding to vibrations of free and bonded $\mathrm{OH}$-groups in the experimental IR spectrum of liquid heptanol.

1. U. Buck and I. Etischer, J. Chem. Phys. 108, 1 (1998).

2. R.A. Provencal, J.B. Paul, K. Roth, R.N. Casaes, R.J. Saykally, G.S. Tschumper, and H.F. Schaefer, J. Chem. Phys. 110, 9 (1999).

3. M.V. Vener and J. Sauer, J. Chem. Phys. 114, 6 (2001).

4. Y.J. Shi, S. Consta, A.K. Das, B. Mallik, D. Lacey, and R.H. Lipson, J. Chem. Phys. 116, 16 (2002).

5. T.D. Fridgen, L. MacAleese, T.B. McMahon, J. Lemaire, P. Maitre, Phys. Chem. Chem. Phys. 8, 955 (2006).

6. S. Coussan, A. Loutellier, J.P. Perchard, S. Racine, A. Peremans, A. Tadjeddine, and W.Q. Zheng, J. Chem. Phys. 107, 17 (1997).

7. Z. Mielke, S. Coussan, K. Mierzwicki, P. Roubin, and M. Saldyka, J. Chem. Phys. 110, 4712 (2006).

8. J.P. Perchard, Chem. Phys. 332, 86 (2007).

9. V. Pogorelov, I. Doroshenko, P. Uvdal, V. Balevicius, and V. Sablinskas, Mol. Phys. 108, 17 (2010).

10. I. Doroshenko, V. Pogorelov, V. Sablinskas, and V. Balevicius, J. Mol. Liq. 157, 142 (2010). 
11. R.W. Larsen and M.A. Suhm, J. Chem. Phys. 125, КВАНТОвО-ХІмІчНЕ МОДЕЛЮвАННЯ КЛАСТЕРНОї $154314(2006)$.

СТРУКТУРИ У РІДКОМУ $N$-ГЕПТАНОЛІ

12. Y. Liu, M. Weimann, and M.A. Suhm, Phys. Chem. Chem. Phys. 6, 3315 (2004).

13. J.P. Toennies and A.F. Vilesov, Angew. Chem. Int. Ed. 43, 2622 (2004).

П.О. Голуб, В.Є. Погорелов, І.Ю. Дорошенко

$\mathrm{P}$ е $з$ ю м е

У даній роботі досліджено різні молекулярні агрегації, що формуються у рідкому гептанолі завдяки водневим зв'язкам. Використовуючи методи квантово-хімічної симуляції, було показано вигідність існування агрегацій, що складаються з п'яти і більше молекул. Правильність зроблених висновків підтверджена порівнянням отриманих результатів з експериментальними даними.

Received 23.09.11 